IZA DP No. 5515

Immigrant Welfare Receipt across Europe

Alan Barrett

Bertrand Maître

February 2011 


\title{
Immigrant Welfare Receipt across Europe
}

\author{
Alan Barrett \\ Economic and Social Research Institute, Dublin \\ and IZA \\ Bertrand Maître \\ Economic and Social Research Institute, Dublin
}

\section{Discussion Paper No. 5515 \\ February 2011}

\author{
IZA \\ P.O. Box 7240 \\ 53072 Bonn \\ Germany \\ Phone: +49-228-3894-0 \\ Fax: +49-228-3894-180 \\ E-mail: iza@iza.org
}

\begin{abstract}
Any opinions expressed here are those of the author(s) and not those of IZA. Research published in this series may include views on policy, but the institute itself takes no institutional policy positions.

The Institute for the Study of Labor (IZA) in Bonn is a local and virtual international research center and a place of communication between science, politics and business. IZA is an independent nonprofit organization supported by Deutsche Post Foundation. The center is associated with the University of Bonn and offers a stimulating research environment through its international network, workshops and conferences, data service, project support, research visits and doctoral program. IZA engages in (i) original and internationally competitive research in all fields of labor economics, (ii) development of policy concepts, and (iii) dissemination of research results and concepts to the interested public.
\end{abstract}

IZA Discussion Papers often represent preliminary work and are circulated to encourage discussion. Citation of such a paper should account for its provisional character. A revised version may be available directly from the author. 
IZA Discussion Paper No. 5515

February 2011

\section{ABSTRACT}

\section{Immigrant Welfare Receipt across Europe*}

The issue of welfare receipt by immigrants is highly controversial across Europe. In this paper, we assess whether immigrants are more likely to receive welfare payments relative to natives across a range of European countries. Using the European Union Survey on Income and Living Conditions for 2007, we find very little evidence that immigrants are indeed more likely to receive such payments when all payments are considered together. This is true whether we use raw data or regression analysis in which we control for relevant characteristics. We do find evidence of higher rates of poverty among immigrants. When combined with the results on welfare receipt, this raises a question over the effectiveness of welfare systems in protecting immigrants from poverty across Europe.

JEL Classification: $\quad$ I38, J61

Keywords: $\quad$ welfare, immigrants, Europe

Corresponding author:

Alan Barrett

Economic and Social Research Institute

Whitaker Square

Sir John Rogerson's Quay

Dublin 2

Ireland

E-mail: Alan.Barrett@esri.ie

\footnotetext{
* The authors are grateful for comments received at seminars on this topic held at the ESRI and the University of Amsterdam and from Christopher T. Whelan. All errors are our own.
} 


\section{Section 1: Introduction}

In public debate, the topic of immigration must rank among the most controversial. Within the subject of immigration, the question of whether immigrants are more or less likely to place demands on the welfare state, relative to natives, is perhaps even more controversial. The question of immigrant welfare receipt relative to natives has motivated a number of papers within the economics literature, with most papers looking at the issue from a national perspective. Examples include Riphahn (2004) on Germany, Hansen and Lofstrom (2009) on Sweden and Barrett and McCarthy (2007) on Ireland. Dustmann et al (2010) also look at this issue but in the broader context of assessing the public finance impacts of immigration into the $\mathrm{UK}^{1}$.

In this paper, we aim to look at relative rates of receipt of welfare across immigrants and natives in a European setting ${ }^{2}$. By using the trans-national European Union Survey on Income and Living Conditions for 2007 (EU-SILC), we are able to assess how rates of welfare receipt for immigrants differ across countries and across payment types. If we observe that immigrants are less likely to receive welfare relative to natives, this would be consistent with a situation in which immigrants face a barrier to receiving payments or that their access is restricted in some way. It could be that they face different eligibility criteria relative to natives. It could also be that they may be unaware of their entitlements. At a more troubling level, to the extent that welfare receipt is dependent upon discretionary decisions of government officials, lower rates of receipt of welfare receipt among immigrants could be consistent with discrimination. Yet another possibility is that immigrants could be less likely

\footnotetext{
${ }^{1}$ For a broad review of the literature on immigration and welfare, see Barrett and McCarthy (2008).

${ }^{2}$ In conducting this analysis, we are updating work by Brücker et al (2002) in which data from 1996 to 1998 was used.
} 
to make claims, if they think that this is in some sense unacceptable in, what is for them, a host country. By extension, if we find no such differential rates of receipt, then concerns on these points are lowered.

We consider the issue using both raw data (Section 2) and regression analysis (Section 3) and generally find very little evidence of higher rates of receipt among immigrants when all payments are considered together. We also look at relative rates of poverty among immigrants and natives and find evidence of higher rates of poverty among immigrants in many countries. When combined with the results on welfare receipt, this raises a question over the effectiveness of welfare systems in protecting immigrants from poverty across Europe.

Section 2: The unadjusted view

In this section we simply compare the proportions of immigrants and natives who receive welfare payments, across countries and across different types of supports. In Section 3 below we consider the question of relative rates of receipt in a multivariate regression context, recognising that differences in these proportions could be the result of differences in socioeconomic characteristics. In so doing, we address the question of whether rates of receipt differ controlling for these socio-economic characteristics. In both Section 2 and 3 we use the European Union Survey on Income and Living Conditions (EU-SILC) for 2007.

Eurostat describe the EU-SILC in the following way ${ }^{3},{ }^{4}$ :

“The European Union Statistics on Income and Living Conditions (EU-SILC) is an instrument aiming at collecting timely and comparable cross-sectional and longitudinal

\footnotetext{
${ }^{3}$ http://epp.eurostat.ec.europa.eu/portal/page/portal/microdata/eu_silc

${ }^{4}$ One very recent example of the use of EU-SILC in the analysis of welfare systems across Europe is Longford and Nicodem (2010)
} 
multidimensional microdata on income, poverty, social exclusion and living conditions. This instrument is anchored in the European Statistical System (ESS).

The EU-SILC project was launched in 2003 on the basis of a 'gentleman's agreement' in six Member States (Belgium, Denmark, Greece, Ireland, Luxembourg and Austria), as well as in Norway. The starting date for the EU-SILC instrument under the belowmentioned framework Regulation was 2004 for the EU-15 (with the exception of Germany, the Netherlands and the United Kingdom, which had derogations until 2005), as well as for Estonia, Norway and Iceland. The 10 new Member States with the exception of Estonia started in 2005.

The instrument has also been implemented in Bulgaria, Romania, Turkey and in Switzerland as from 2007. Implementation in Croatia is being discussed.

The instrument aims to provide two types of data:

- Cross-sectional data pertaining to a given time or a certain time period with variables on income, poverty, social exclusion and other living conditions

- Longitudinal data pertaining to individual-level changes over time, observed periodically over, typically, a four year period.

Social exclusion and housing condition information is collected at household level while labour, education and health information is obtained for persons aged 16 and over. The core of the instrument, income at very detailed component level, is mainly collected at personal level but a few components are included in the household part of SILC.”

Before looking at the question of supports, we first look at the proportions of immigrants living in countries across Europe. We should point out at this stage that we imposed a rule whereby only countries with at least 100 immigrants are included, so as to ensure that the figures produced later are based on a reasonably sized sample of immigrants. Although our definition of an immigrant is a person who was not born in their current country of residence, most countries identify two groups of foreign-born people - those who were born within the European Union and those born outside of European Union. Hence in our country surveys we distinguish between EU and non-EU immigrants and we present all findings by looking at these two groups separately. The one exception is Germany. We can only identify foreignborn people and not whether they come from within or outside the European Union. In all the 
figures we show the result for Germany; however it should be noted that the information presented refers to all foreign-born.

Figure 1: Percentage of immigrants across countries

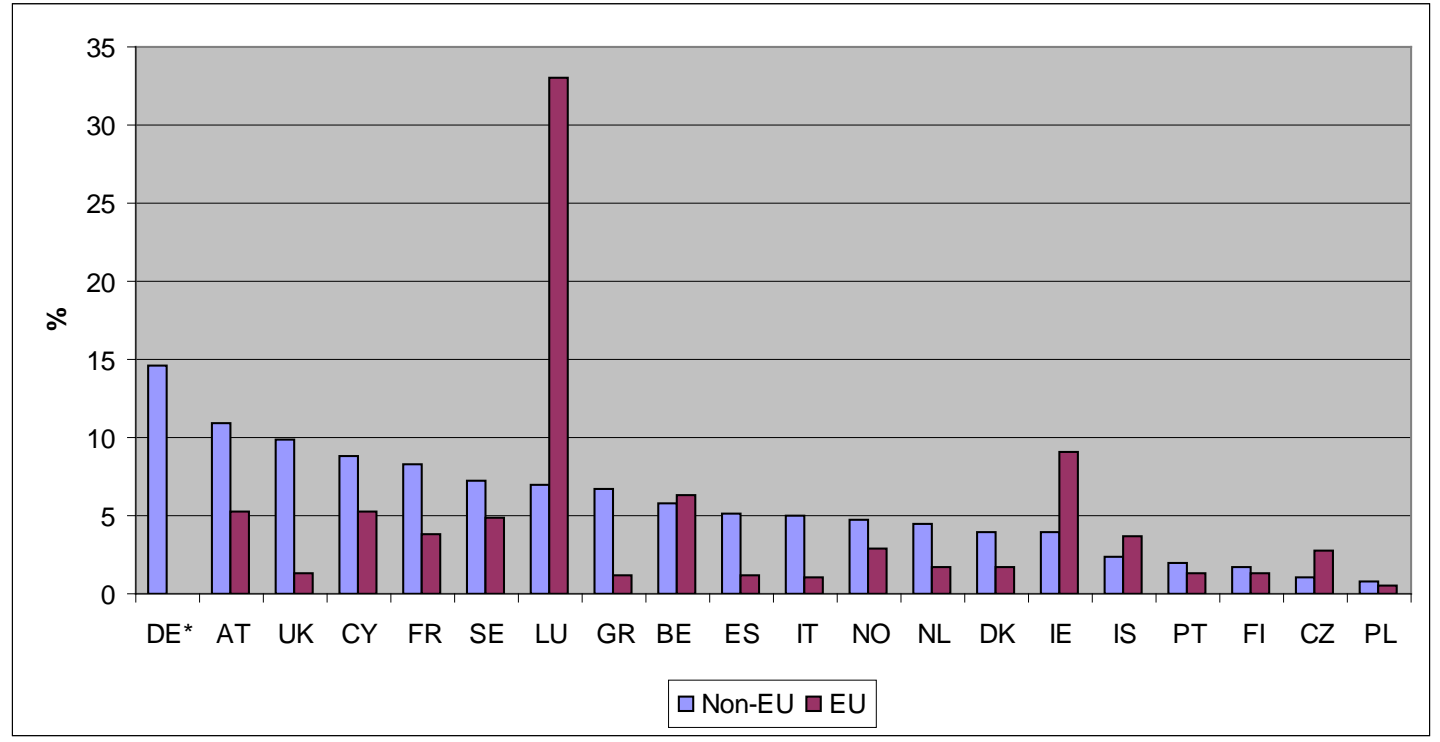

* Notes: EU SILC 2007. *All immigrants for Germany.

In Figure 1 we show the proportions of non-European Union and European Union immigrants across the countries. In this figure and in subsequent ones, we rank the countries according to the proportion of non-European Union immigrants. According to the EU-SILC data, Austria has the highest proportion of non-European Union immigrants. It is generally the case that the number of non- European Union immigrants exceeds that of EU immigrants, with the exceptions to this being Luxembourg, Ireland, Iceland and the Czech Republic.

We now turn to the question of social supports. We begin by looking at a range of social supports combined. These are payments related to the following circumstances: unemployment, sickness, disability and old-age, and payments related to having children. At this stage we are considering all individuals in the adult population. In Figure 2 and the 
following ones, we show the ratio of the proportion of immigrants in receipt of supports to the corresponding proportion of natives. ${ }^{5}$ Ratios that exceed one imply that the proportion of immigrants is higher than the proportion of natives; the opposite holds for ratios below one. In presenting the ratios we rank the countries so that the first country has the highest ratio for non-EU immigrants relative to natives. The ratio in respect on EU immigrants is also shown for each country. Where a white bar appears, this means that there was not a statistically significant difference between the relevant proportions.

Figure 2: Ratio of proportions of immigrants and natives: All types of support

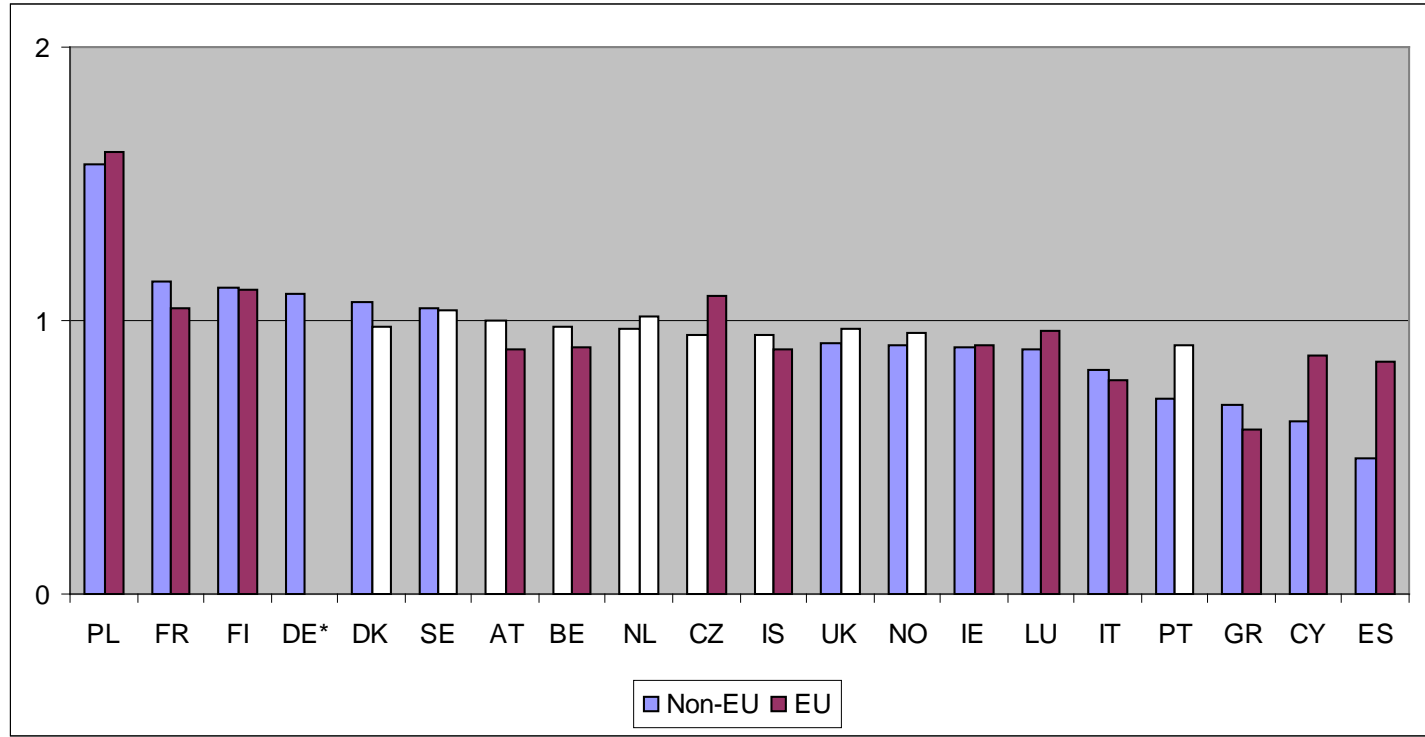

Notes: EU SILC 2007. *All immigrants for Germany.

Looking across Figure 2 we can see that Poland, France, Finland, Sweden and Denmark are countries in which the proportion of non-EU immigrants receiving supports exceeds that of the native born. Poland appears to be something of an outlier with a ratio of 1.57 (non-EU to native). It is interesting to see that for three of these countries (Poland, France and Finland)

\footnotetext{
${ }^{5}$ For example the ratio for non-EU immigrants in Poland in Figure 2 is calculated as follows. The proportion of non-EU immigrants in Poland who received any form of social payment is $85.3 \%$. The corresponding proportion for Polish natives is $54.4 \%$. Dividing 85.3 by 54.4 gives a ratio of 1.57 .
} 
the ratio in respect of EU immigrants and natives also exceeds one. This is somewhat unusual across the countries, with the Czech Republic being the only other country where EU immigrants are seen to have a higher rate of social support receipt relative to natives.

From Figure 2 we can see that lower rates of receipt for immigrants relative to natives are more typical across the countries. Of the nineteen countries listed (excluding Germany), rates of receipt are lower (and statistically so) for non-EU immigrants in nine. For a further five countries, there is no statistically significant difference between rates of receipt for non-EU immigrants and natives. A similar pattern holds in respect of EU immigrants, with lower or statistically equivalent rates of receipt being more prevalent.

Figure 3: Ratio of proportions of immigrants and natives: Unemployment supports

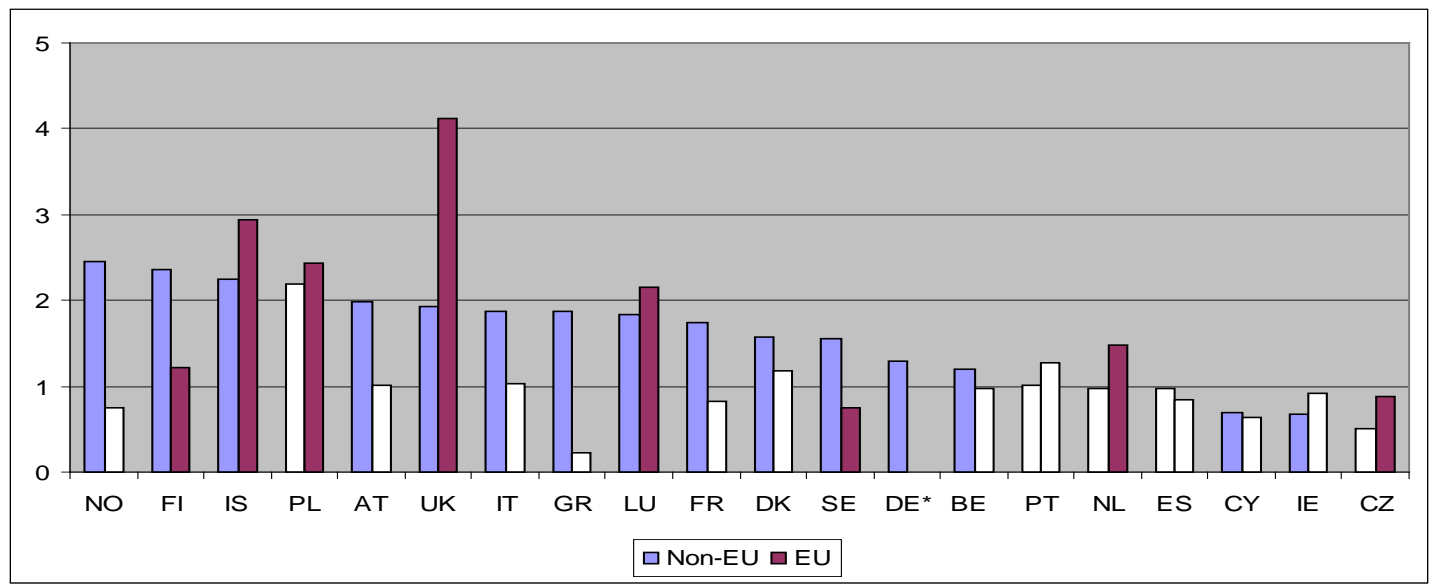

Notes: EU SILC 2007. *All immigrants for Germany.

In Figure 3, we begin to look at supports in a more disaggregated way - in particular we look at rates of receipt by types of support. The ratios shown in Figure 3 are based on receipt of unemployment related supports. Given the nature of these payments, we restrict our analysis to individuals of working age. 
Relative to Figure 2, Figure 3 contains a somewhat different picture. Recalling that ratios over one imply higher rates of support receipt for immigrants relative to natives, there appears to be a stronger tendency for higher rates of receipt of unemployment supports among non-EU immigrants. Across the 19 countries, 12 countries show ratios above one for non-EU immigrants; a further two also have ratios above one, but these are not statistically significant. In the case of Norway, Finland and Iceland, the ratio exceeds two.

Figure 4: Ratio of proportions of immigrants and natives: Old-age support

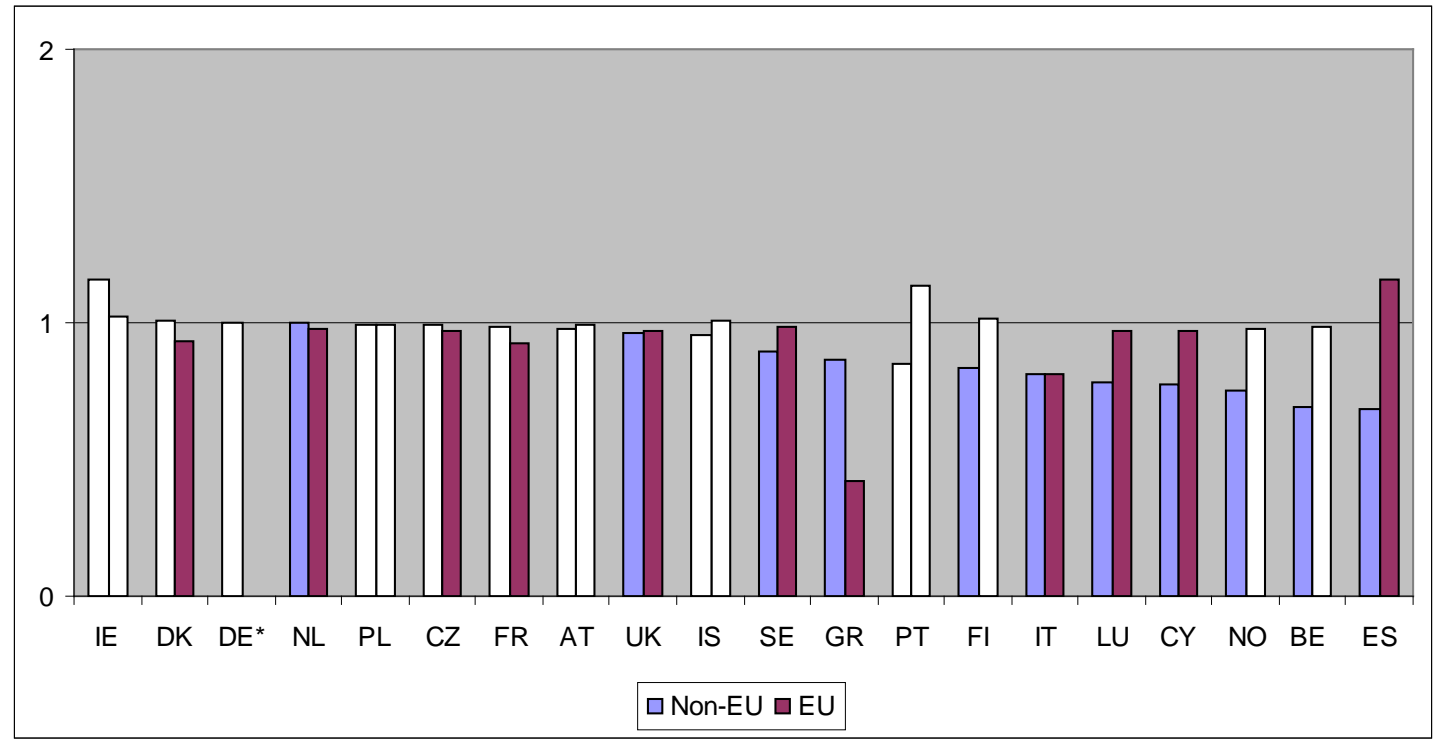

Notes: EU SILC 2007. *All immigrants for Germany

In Figure 4 we consider supports that are related to old-age. Given the nature of the support in question, we now restrict the sample to people who are aged over 65. Just as there are differences between the patterns shown in Figures 2 and 3, there are also striking differences between Figures 2 and 4 . For the vast majority of countries immigrants are either as likely or less likely to be in receipt of old-age support.

We turn next to sickness and disability supports. When calculating these ratios, we only examine the working age population on the basis that people aged over 65 are more likely to 
be in receipt of old-age supports if they are eligible for some form of state support. The ratios are shown in Figure 5. The general picture in Figure 5 is more similar to that in Figure 4 as opposed to that in Figure 3, with the tendency being for immigrants to have lower rates of receipt. There is no country in which non-European Union immigrants are more likely to be in receipt of these payments. One notable feature in the figure is the apparent high rate of receipt of supports of European Union immigrants in Portugal.

Figure 5: Ratio of proportions of immigrants and natives: Sickness/disability support

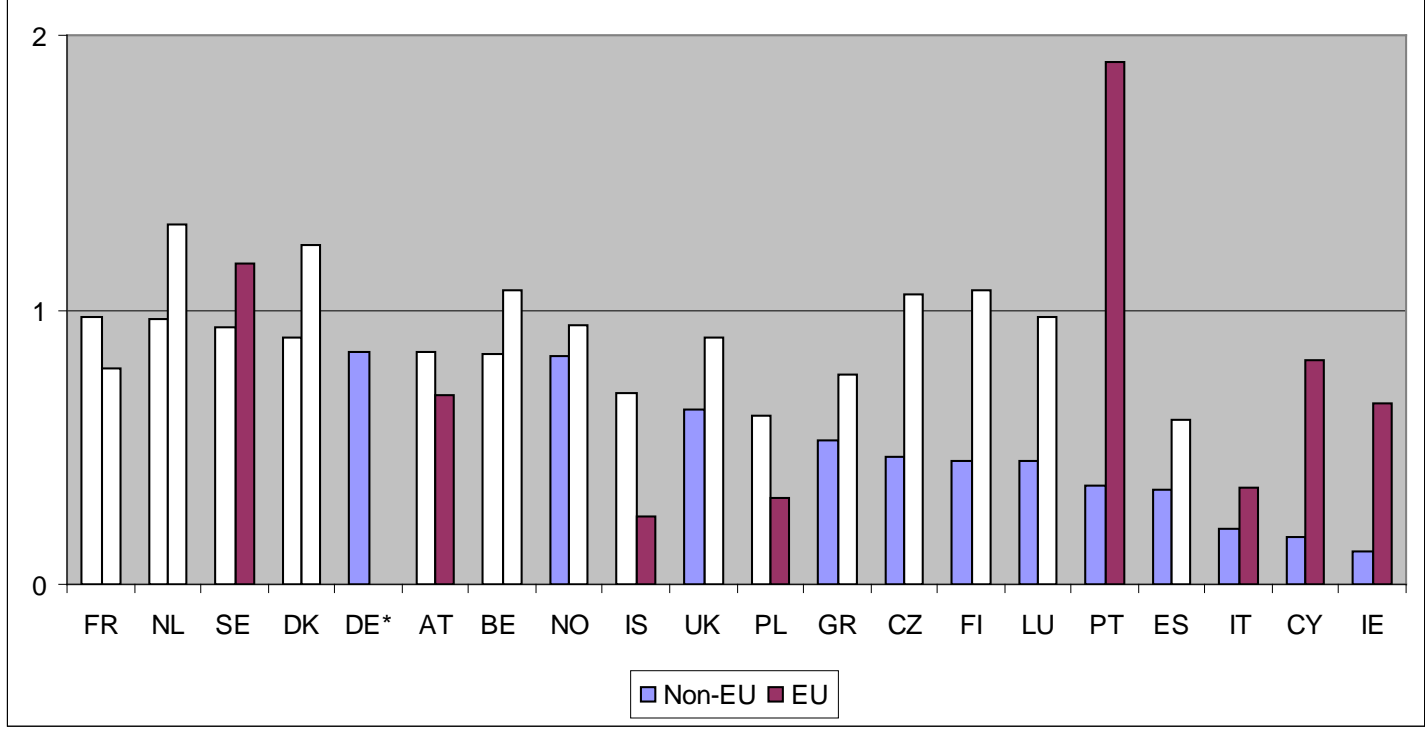

Notes: EU SILC 2007. *All immigrants for Germany.

The last set of support to be considered is the one given when children are present in the household. Given the structure of the data, we are not necessarily looking at the parents of children in the household; all we can say is that we know for each individual if there are children in the household and if family-related supports are paid into the household also. For these supports we revert to looking at the entire populations of immigrants and natives. The ratios are shown in Figure 6, and the broad picture that emerges is one of higher rates of 
receipt among the non-EU immigrants relative to the native population. Only two countries, Cyprus and Poland, have ratios for the non-EU immigrants which are lower than one, with proportions that are statistically different. The ratio for the Czech Republic is also lower than one but the difference in the proportions for non-EU immigrants and natives is not statistically significant. At the other end of the figure, Finland, Denmark, Sweden and France have ratios that exceed 1.5 .

Figure 6: Ratio of proportions of immigrants and natives: Family/child support

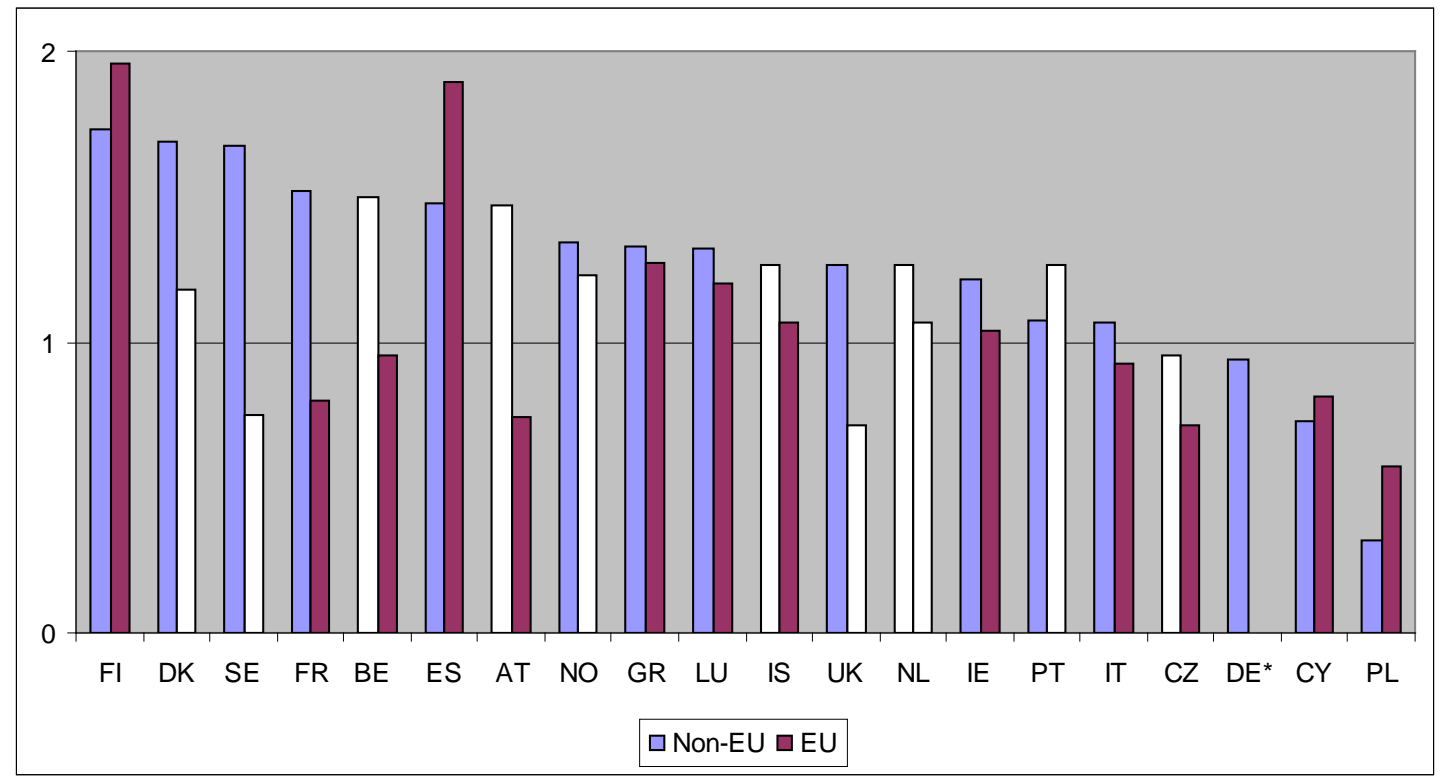

Notes: EU SILC 2007. *All immigrants for Germany.

These ratios are interesting but they also point to a potentially simple explanation for immigrants/native differences: namely higher numbers of children in immigrant households. Below we explore this more fully when we move onto the regression-based analysis.

Before leaving this section on descriptive analysis, it is useful to look at another set of ratios but this time with a focus on risk of poverty as opposed to rates of receipt of supports. We calculated what proportion of immigrants and natives live in households in which income is 
below 60 percent of median household income. In Figure 7 we show the ratios of these proportions along the lines of Figures 2-6.

Figure 7: Ratio of proportions of immigrants and natives at risk of poverty

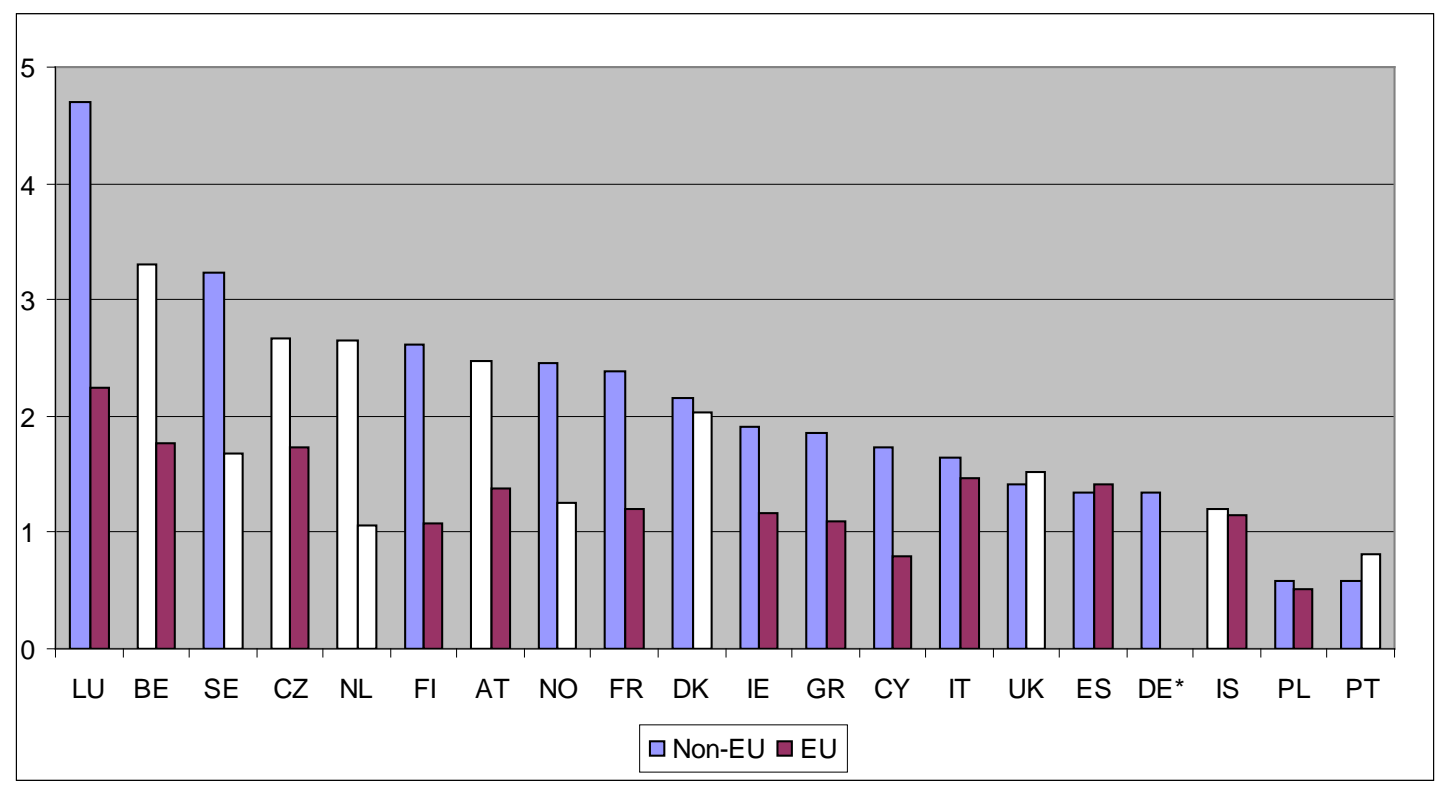

Notes: EU SILC 2007. *All immigrants for Germany.

Figure 7 appears to reveal a general tendency for non-EU immigrants to face a higher risk of poverty than natives across a broad range of countries. The ratio is below one in just two cases - Poland and Portugal. Twelve countries show ratios greater than one, where proportion differences are statistically significant. In six of those twelve countries, the ratio is higher than 2, and in two - Luxembourg and Sweden - the ratio is higher than 3. For immigrants from within the European Union, the general tendency is also for higher rates of being at risk of poverty relative to natives. Only in Poland and Cyprus is there clear evidence of the poverty risk being lower for European Union immigrants relative to natives. The ratios are typically lower for European Union immigrants when compared with the non-European Union immigrants/native ratios but are generally greater than one. 
Section 3: The adjusted view

In Section 2 we set out the results that emerge from a straightforward comparison of the proportions and immigrants and natives who receive social supports. As mentioned the patterns observed could be the result of immigrants and natives differing in terms of relevant socio-economic characteristics. If this were the case, there would be no immigrant-specific effect on the pattern of support receipt. It is important to gain a clearer insight into this possibility, partly from a policy perspective. For example if immigrants are more likely to receive unemployment support relative to natives after controlling for factors such as work experience and education, it suggests that immigrants face labour market difficulties that are associated with their status as immigrants. Hence immigrant-specific policies might be required. This would not be the case if any differences in the rate of receipt between immigrants and natives disappeared once relevant socio-economic characteristics were controlled for.

Before presenting the regression results, it is useful to present some data on the relative characteristics of immigrants and natives across the countries in question. As is the case above, we present information on the characteristics in terms of ratios. In Figure 8 we examine the average ages of immigrant and native populations. Ratios greater than one imply that immigrants are older, on average, relative to natives; ratios less than one imply the opposite. We have not presented measures of statistical significance.

A clear picture emerges from Figure 8 of immigrant populations generally being younger than native populations, especially in the case of non-European Union immigrants. For just three countries the non-European Union immigrant group is older than the native group. For non-European Union groups the ratio is below $80 \%$ in Italy, Norway, Ireland and Portugal. 
The European Union immigrant groups are generally younger than the native populations too, although younger than the non-European Union immigrant groups in their respective host countries.

Figure 8: Ratios of average ages of immigrants and natives

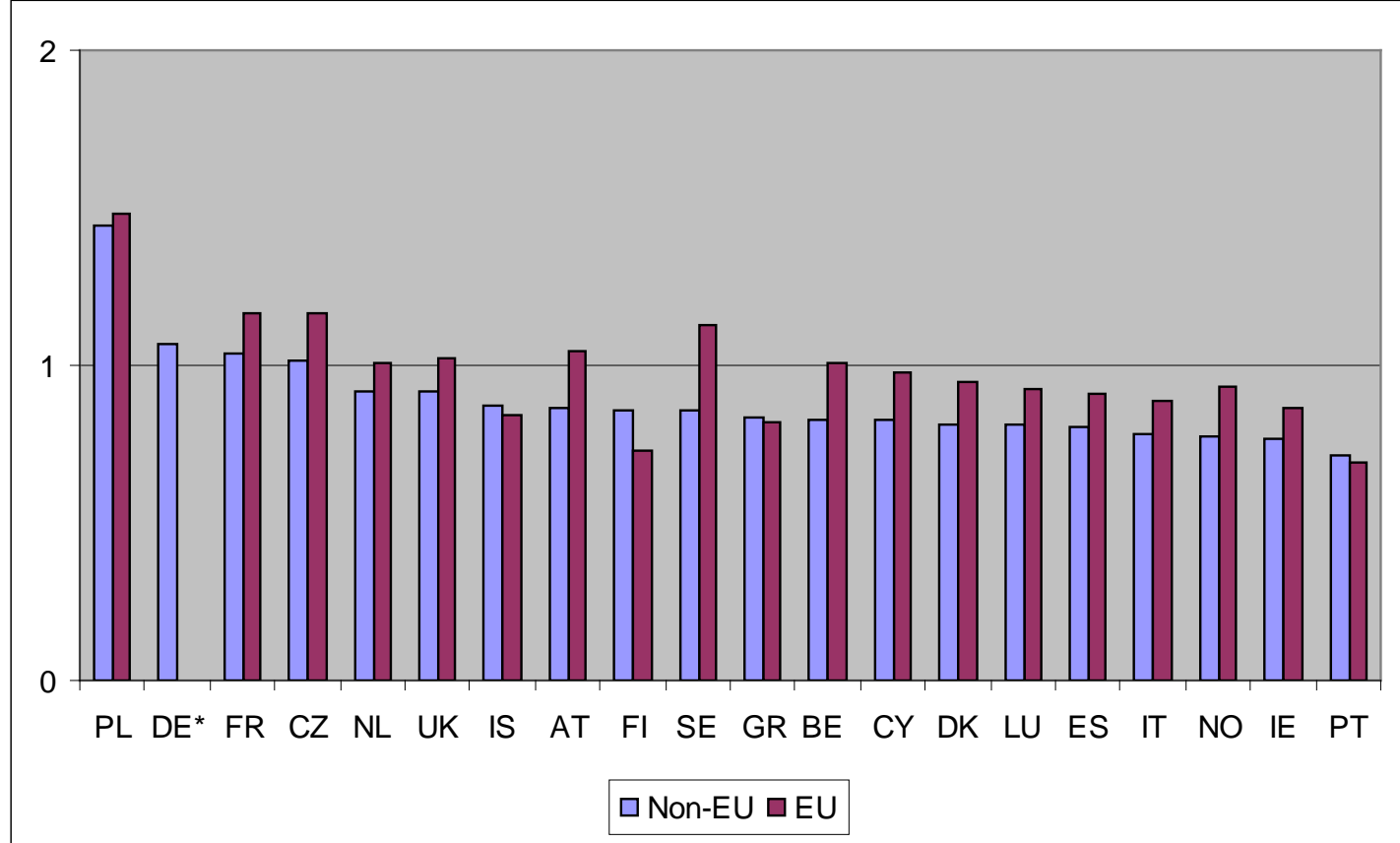

Notes: EU SILC 2007. *All immigrants for Germany.

As a second element in this assessment of how the immigrant and native populations differ in terms of characteristics, we look at educational qualifications. Although the data contain information on a number of educational categories, we have chosen to focus on one category to make the presentation of the data more accessible. In Figure 9 we construct ratios based on the proportion on immigrants and native who report having completed "post-secondary or tertiary education.” In this way we focus on the higher end of the educational distributional and assess the relative qualifications of immigrant and native populations from this perspective. 
Looking across the figure and focussing on the non-European Union immigrants, there appear to be three groups of countries. From Ireland through Finland, the non-European Union immigrants have higher levels of educational attainment relative to natives. We take Finland to be part of this group as its ratio is over 1.1. From the Netherlands through Spain, the ratio is between 1.1 and 0.9 , and so these countries can be thought of as having similar levels of education among their non-EU immigrants and their native populations. The final three countries have ratios below 0.8. For the EU immigrants groups there are a larger number of countries where the ratio exceeds one by a considerable amount. Taking 1.1 as a cut-off, 11 countries have ratios which exceed this. Norway, Denmark and Austria are notable for the extent to which the educational qualifications of the European Union immigrants are greater than those of the non-European Union immigrants.

Figure 9: Ratios of proportions of immigrants and natives with post-secondary and tertiary educations

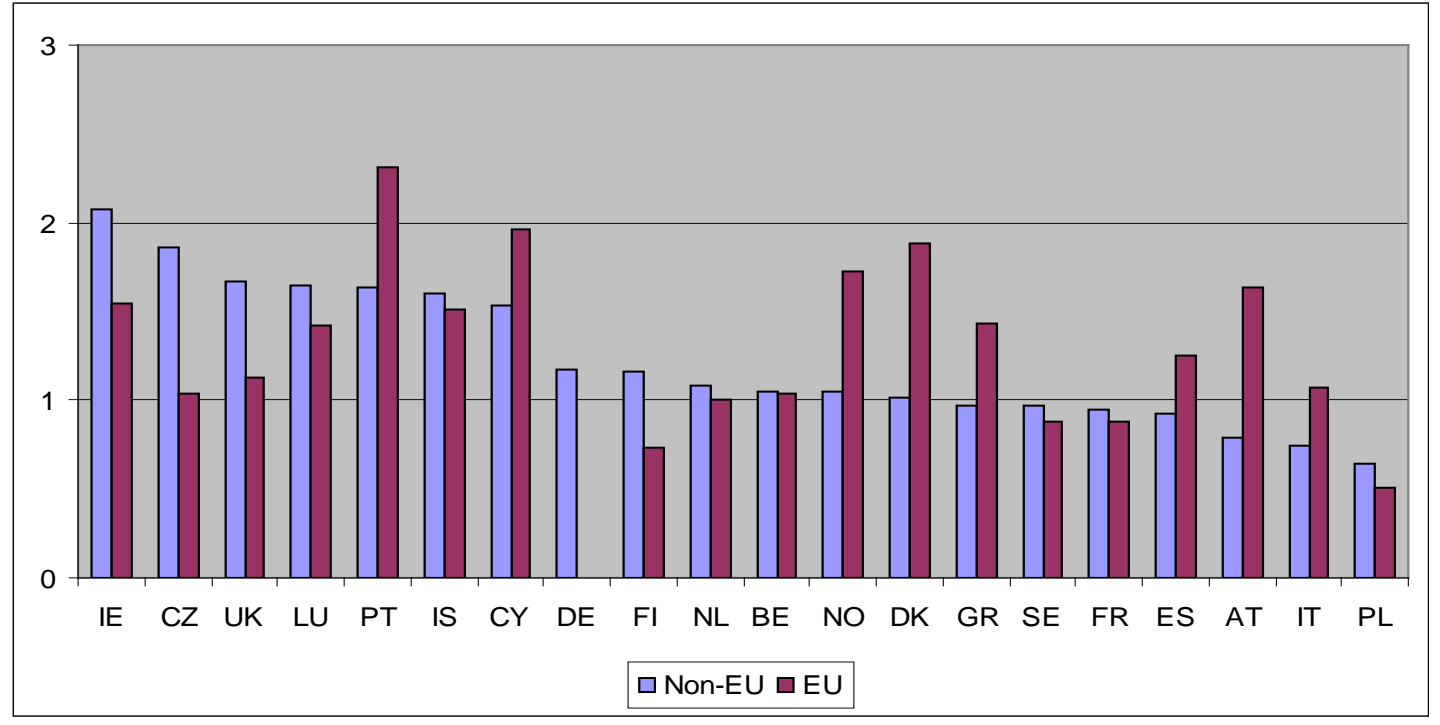

Notes: EU SILC 2007. *All immigrants for Germany.

As the immigrant populations are generally younger than the native populations, we would expect them to have lower amounts of labour market experience also. This is seen in Figure 
10 below. We only have information on this variable for a limited number of countries but the pattern is clear. In only one country do we see that non-EU immigrants have longer periods of years worked (Poland). And in only three do we see this applying for EU immigrants (Poland, France and the Czech Republic). The impact of these lower amounts of labour market experience on welfare receipt is unclear, however. People with lower labour market experience are typically more vulnerable to unemployment; however, an employment record of a certain duration is often needed in order to qualify for benefits.

Figure 10: Ratios of average number of years worked of immigrants and natives

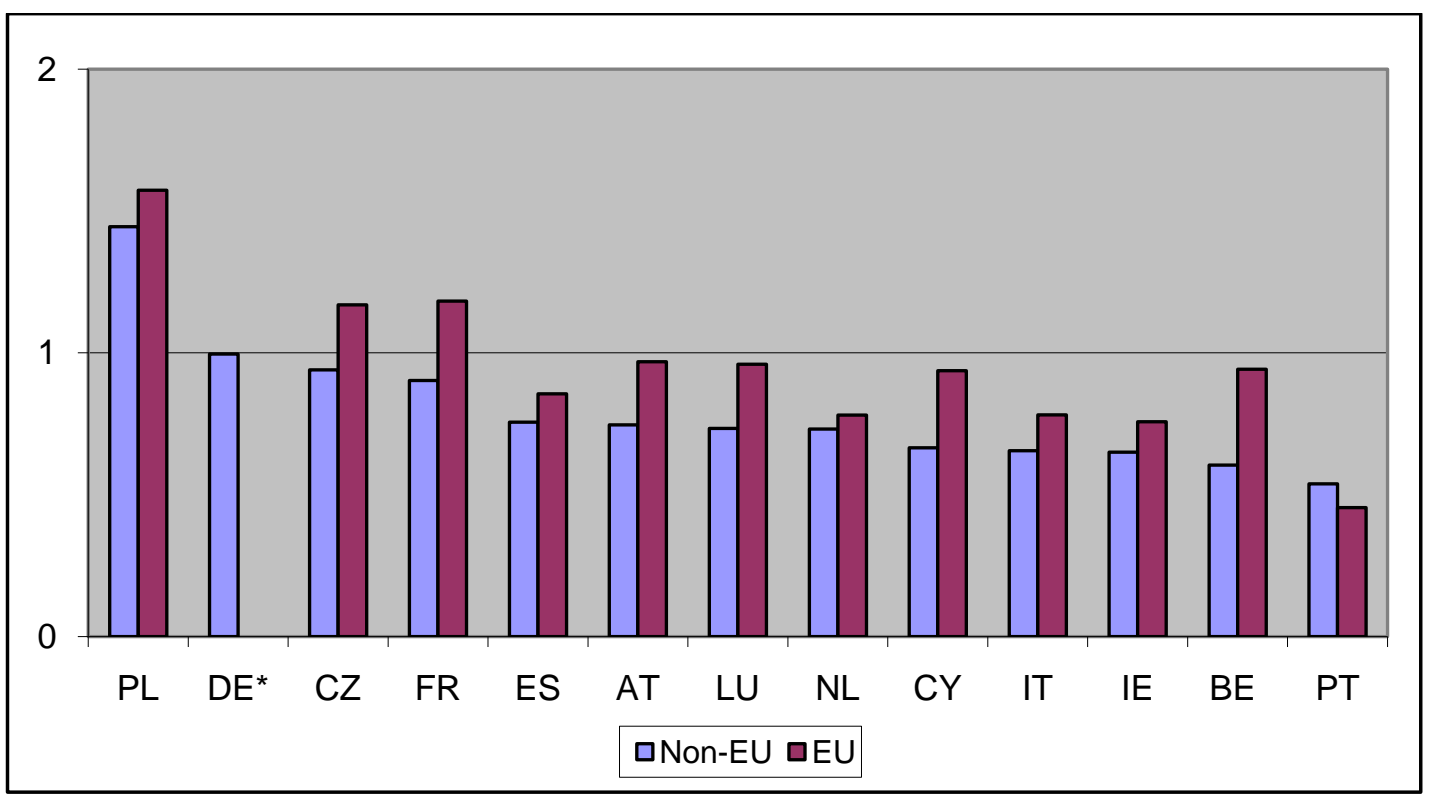

Notes: EU SILC 2007. *All immigrants for Germany.

The fourth and final characteristic that we will look at it number of children. As many countries provide welfare benefits based on the presence and number of children, it is clear that this could be a significant determinant of differences across immigrants and natives in terms of welfare receipt. In Figure 11 we show the ratios of the average number of children across immigrants and natives. As can be seen, it is generally the case that immigrants from outside the EU have higher numbers of children. The ratio is higher than 1.1 for the first six 
countries show and is greater than 1 for fifteen of the countries. For immigrants from within the EU, there is a general tendency to have lower numbers of children relative to the native populations.

Figure 11: Ratios of average number of children

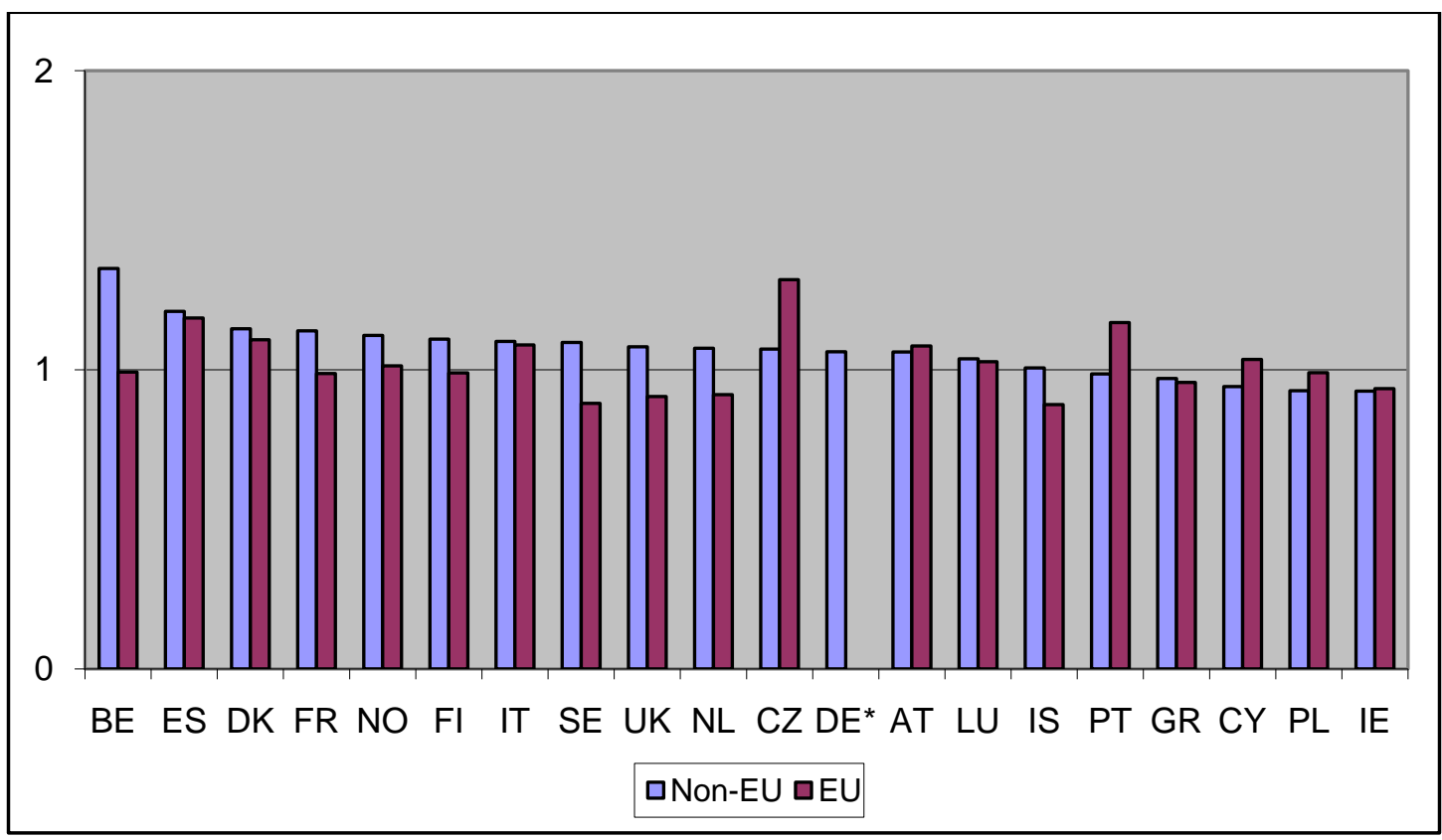

Notes: EU SILC 2007. *All immigrants for Germany.

In the regression results presented below, we reconsider the question of the relative rates of receipt of supports across immigrants and natives, controlling for relevant factors. In the following figures, we present results from these regressions in the following way. We show the estimated marginal impact of being an immigrant on the likelihood of receiving social supports, having controlled for gender, age, education and the number of children in each individuals household. The regressions used are probit regressions, as this approach is typically used in situations where the dependent variable is binary in nature, i.e. the person either did or did not receive a payment. As before we rank the countries in terms of the estimated marginal impacts for non-European Union immigrants. 
Our first regression includes all individuals in the sample and we include the receipt of all the same payments as considered in Figure 2 above, i.e. unemployment, sickness, disability and old-age, and child-related payments. The estimated marginal effects are shown in Figure 12. As was the case with the ratios in Figure 2-7 above, white bars imply non-statistically significant results.

Figure 12: Estimated marginal impact of immigrant status on support receipt: All types of support

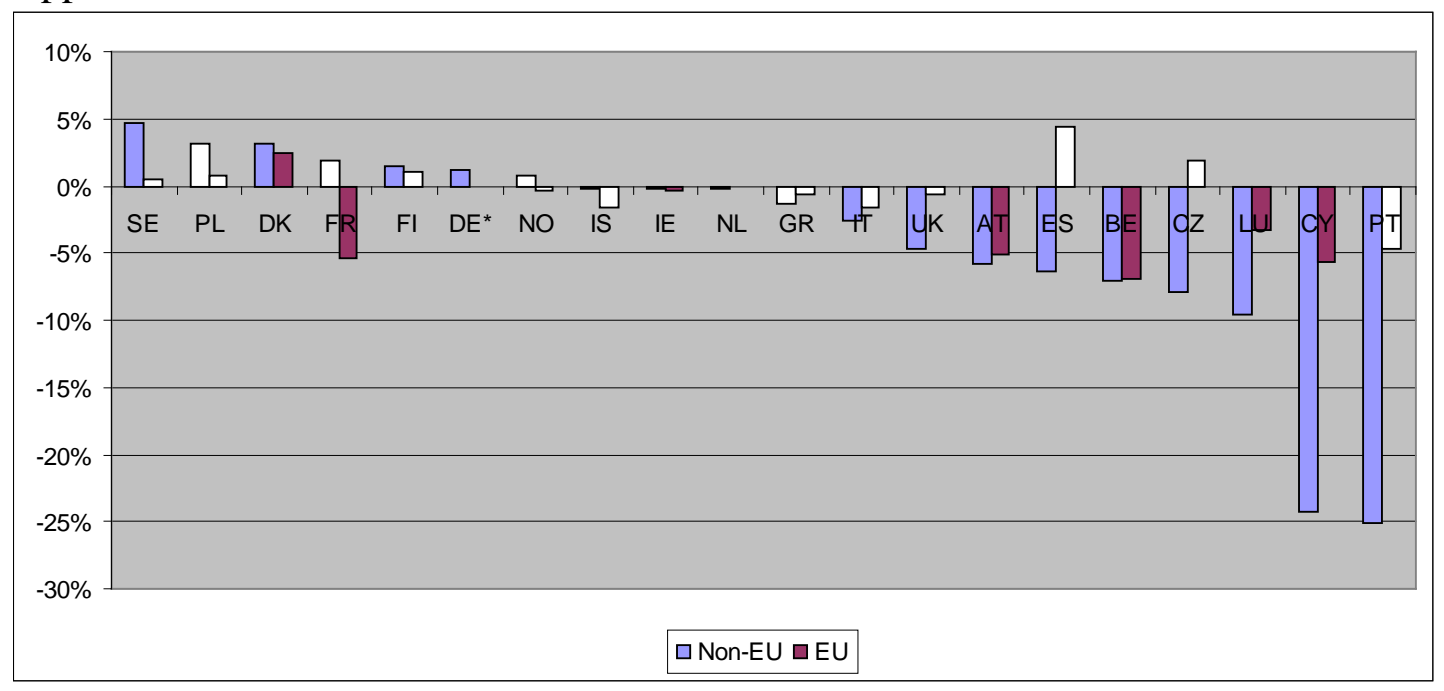

Notes: EU SILC 2007. *All immigrants for Germany.

Figure 12 generates a general pattern of lower rates of receipt among immigrants relative to natives, controlling for the factors listed above. Sweden, Finland and Denmark are the only countries in which higher (and statistically significant) rates of receipt among immigrants are observed. These countries showed similar outcomes in Figure 2 when unadjusted data was presented, so, from this perspective at least, the controls which we added have not altered the picture substantially. 
We know from Figures 2-6 that the pictures of relative receipt of supports can change by benefit type, so in Figure 13 we show the regression results when we restrict our attention to the following supports: unemployment, sickness and disability. We also restrict the sample to those of working age. As with the comparison between Figures 2 and 12, the comparison between Figures 3 and 13 shows a somewhat greater tendency for immigrants to receive supports when attention is restricted to this more narrow set of supports. However of the 19 countries in the figure, rates of receipt for non-European Union immigrants are statistically higher in just seven; hence in 12 countries the differences are either indistinguishable from zero or less than zero. The higher rates of receipt in Finland and Denmark point to the possibility of a regional effect.

Figure 13: Estimated marginal impact of immigrant status on support receipt: unemployment, sickness and disability

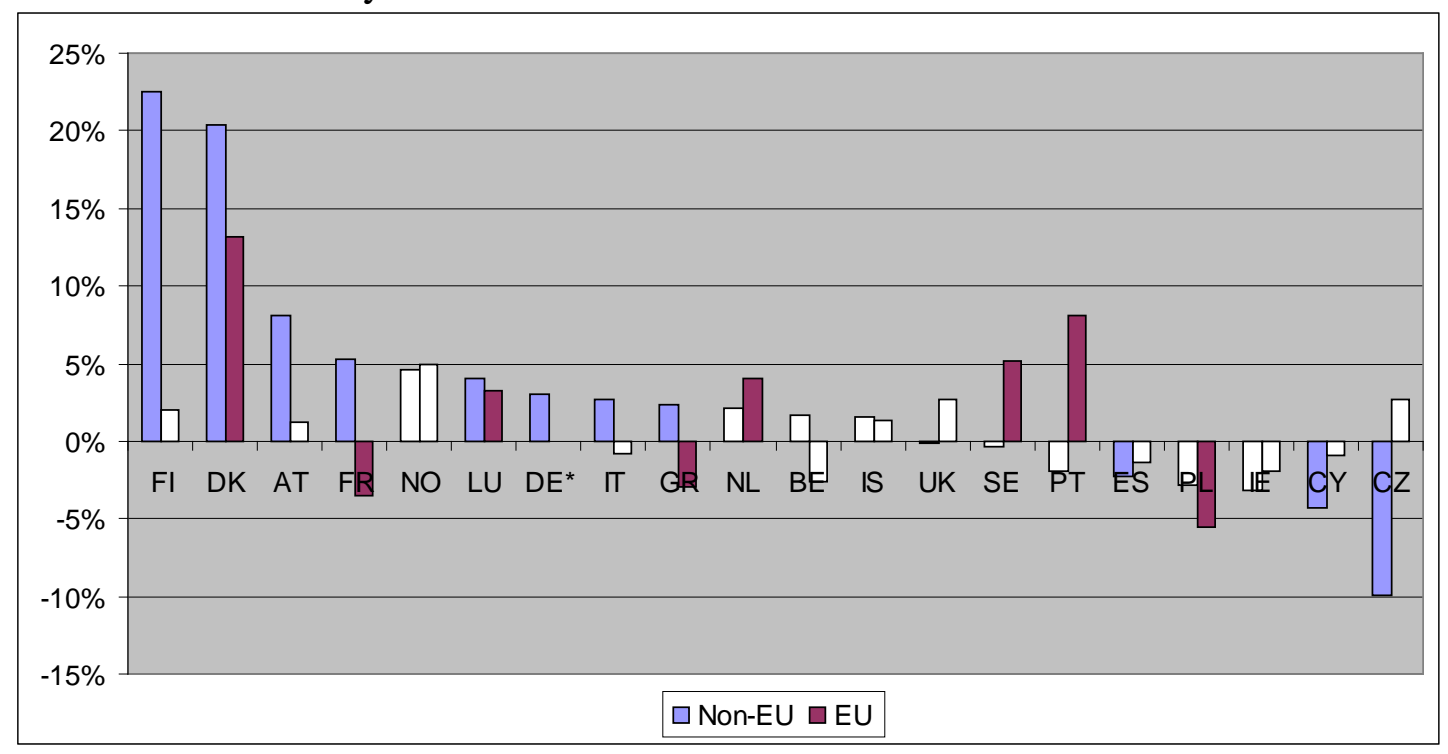

Notes: EU SILC 2007. *All immigrants for Germany.

In Figure 14 we look at old age support, having restricted the analysis to those aged over 65. Relative to Figures 4.3 and 4.4 the picture is very clear with almost no immigrant group showing a greater likelihood to be in receipt of old age support. 
Figure 14: Estimated marginal impact of immigrant status on support receipt: Old age

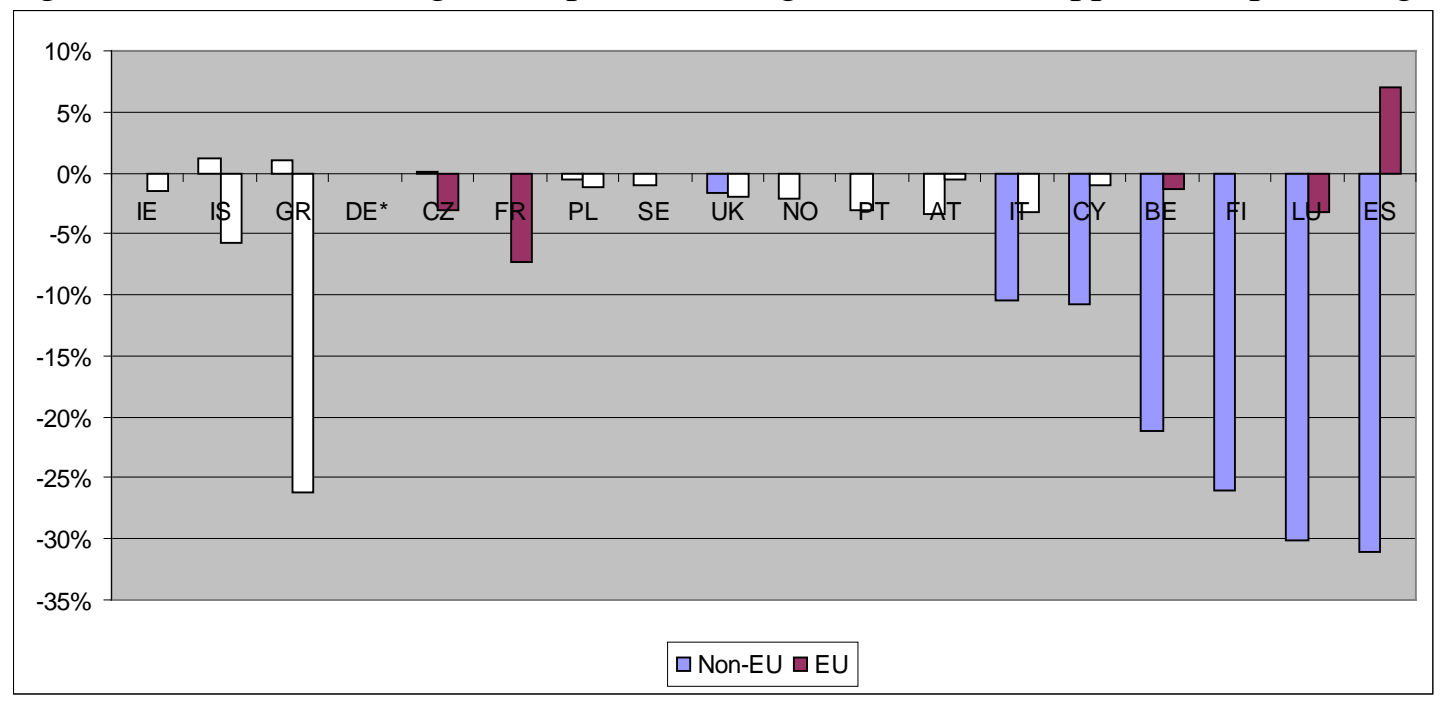

Notes: EU SILC 2007. *All immigrants for Germany.

Spain provides an interesting exception as the only country where there is a higher rate of receipt among European Union immigrants that is statistically significant. This could be the result of Spain being a retirement destination for northern Europeans. If this is the case, then the supports could be coming from governments other than Spain.

Figure 15: Estimated marginal impact of immigrant status on support receipt: family/child support

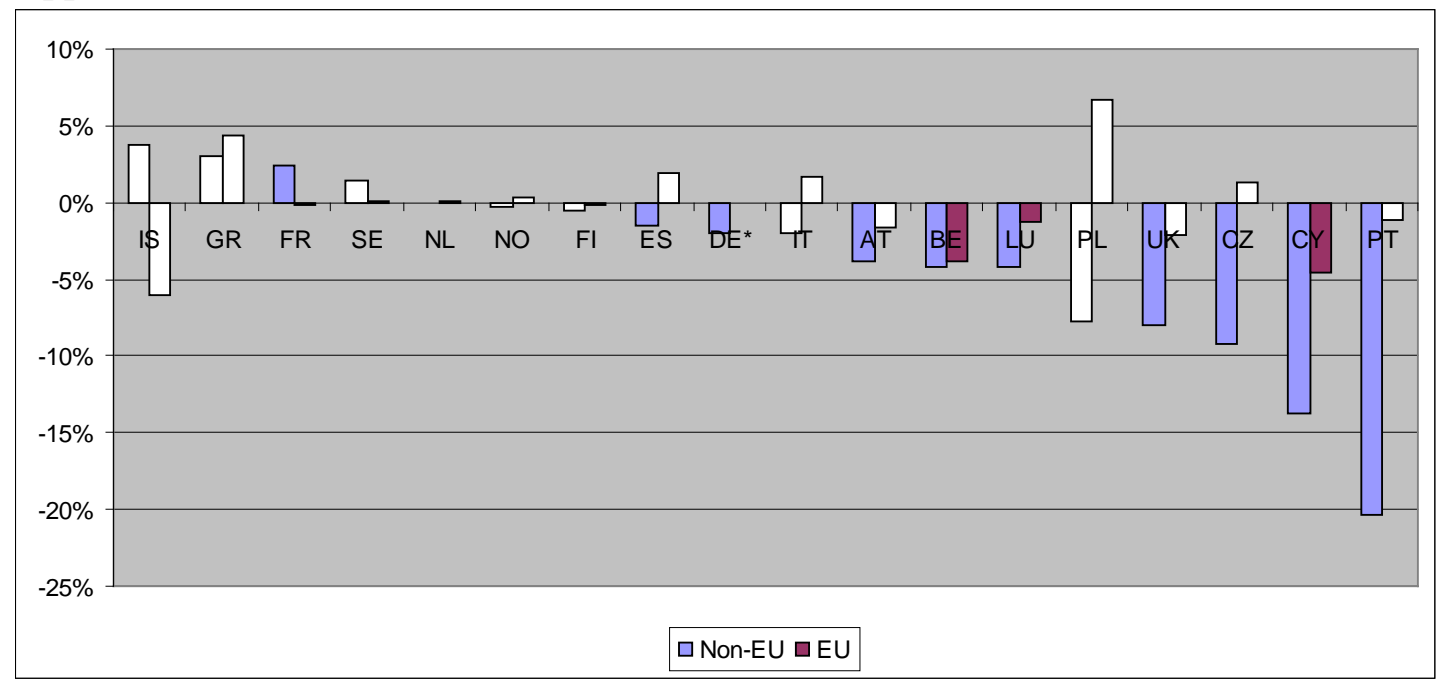

Notes: EU SILC 2007. *All immigrants for Germany. 
The final set of support considered is family-related payments. The results from this regression are show in Figure 15, and the degree of clarity that was apparent in Figure 14 (old age supports) is present once again. With only one exception, and where results are statistically significant, immigrants are less likely to be in receipt of family-related payments. France is the only exception: non-European Union immigrants are $2.5 \%$ more likely to receive such supports.

We have now examined all types of support, but there are two remaining issues that are worthy of consideration. We are generally finding that immigrants (especially those from non-European Union countries) are either as likely or less likely to be in receipt of support relative to natives. Two questions that arise are the following. First, to the extent that social supports are supposed to keep people out of poverty, are the lower rates of receipt among immigrants associated with higher risks of poverty? Second, are rates of receipt among immigrants lower even when we restrict our attention to groups of immigrants and natives who might be similar in terms of eligibility for benefits?

We touched on the question of poverty in Figure 7 above where proportions of immigrants and natives at risk of poverty are examined without controlling for any socio-economic factors. In Figure 16 we show the estimated marginal impacts having controlled for age, education, gender and number of children. The results are striking, especially when compared to some of the earlier figures. A quick glance of Figures 10-13 reveals the presence of many white bars and for unemployment, sickness and disability support, a scattering of lines above and below the zero line. However in Figure 16 there are no negative and statistically estimates, so lower rates of poverty among immigrant groups are nowhere to be seen. Instead all the significant estimates are positive and this applies to both European Union and non- 
European Union immigrants. In addition to the positive estimated marginal effects, the magnitudes of the effects are also large. In nine of the countries, non-EU immigrants are more likely to be at risk of poverty by $10 \%$ or more.

Figure 16: Estimated marginal impact of immigrant status on support receipt: At risk of poverty

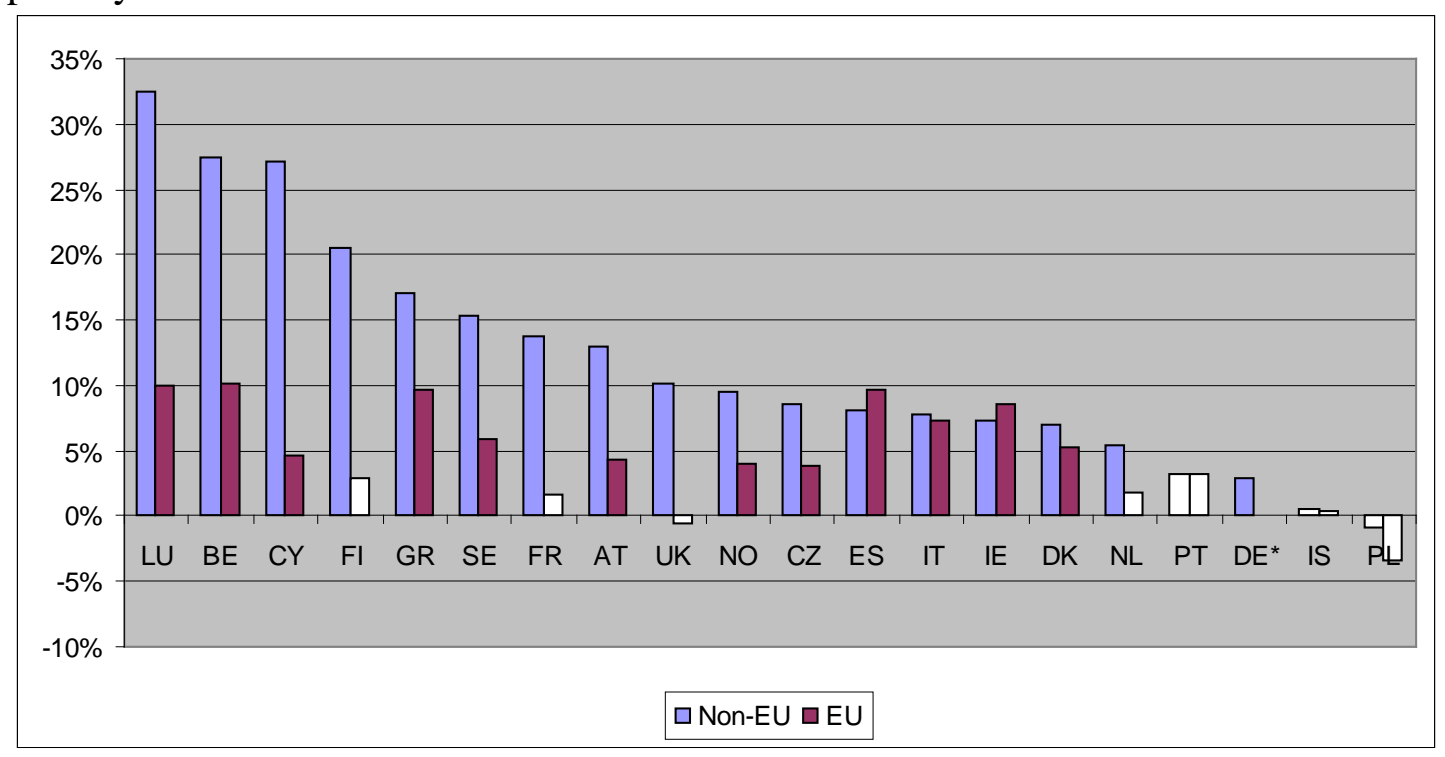

Notes: EU SILC 2007. *All immigrants for Germany.

Our final regression results attempt to provide some insight on the issue of benefit receipt among groups with similar eligibility. We examine the likelihood of receiving unemployment support in 2006 for people who were unemployed in 2007. Obviously we would like to have had contemporaneous information on unemployment and support receipt but this is not possible from the data. But to the extent that being unemployed in 2007 is an indicator of being at risk of unemployment in 2006, the results might provide some insight. The results are shown in Figure 17.

Most of the results from this set of regressions are non-significant. However where significant results emerge, they tend to suggest lower rates of receipt by unemployment 
immigrant relative to unemployed natives. This could reflect differences in eligibility across unemployed people. For example a certain amount of social insurance payments may be needed in order to qualify for supports. However this could also reflect a lower tendency to apply for benefits in the context of equal eligibility.

Figure 17: Estimated marginal impact of immigrant status on support receipt: Unemployment support for those who are unemployed

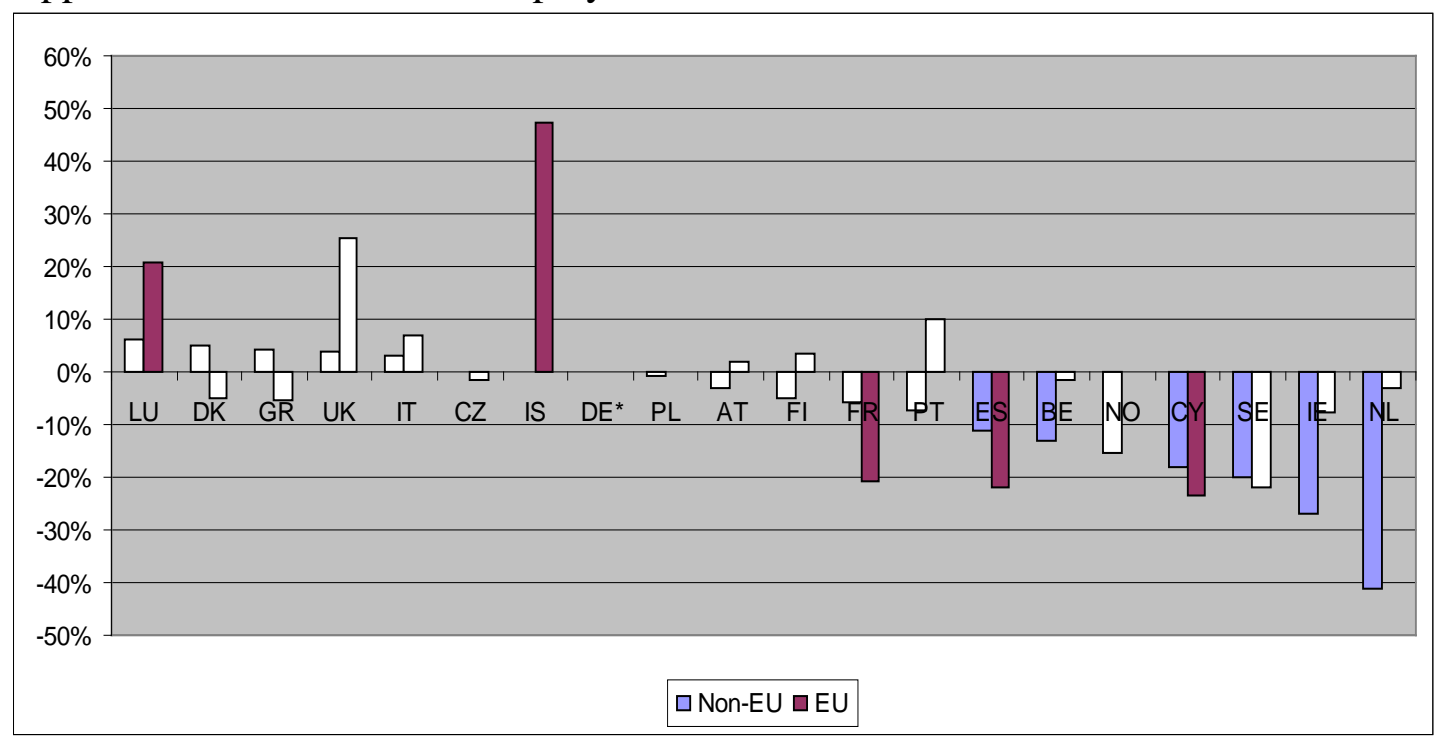

Notes: EU SILC 2007. *All immigrants for Germany.

Section 4: Summary and conclusions

In summary the descriptive analysis suggests that across all social support payments, there is generally little evidence that immigrants are excessive users relative to natives. Immigrants are more likely to be in receipt of unemployment related supports in a wide range of countries and also of family-related payments. They are less likely to receive old age payments and sickness/disability payments. However, the most clear-cut result to emerge from this element of the analysis was the greater likelihood of immigrants being in poverty. The picture that emerges from Figure 7 is striking in that it shows a clear and unambiguous pattern of poverty risk among immigrants that exceeds that of natives. 
Echoing what was found in Section 2, but to a stronger degree, the broad conclusion to be drawn from the regression analysis is that there is little evidence of excessive receipt of support by immigrants relative to natives, where "excessive" is defined as higher rates of receipt whether adjusting for socio-economic characteristics or not. To the extent that higher rates of receipt are present, they appear to be restricted to unemployment support; but even in this case, this only applies in a restricted number of countries. But as with the analysis in Section 2, what is perhaps more striking are the higher rates of poverty among immigrants.

Given the higher rates of poverty and the lower rates of welfare receipt, the questions that arises are whether welfare systems are failing to protect immigrants and if so, why. These are clearly important issues and deserving of further discussion and analysis. To a certain extent, the focus in much of the popular discussion of immigrants and welfare has been on concerns about excessive use on the part of immigrants and this may have distracted from the bigger policy concern apparent here. If welfare systems are indeed failing to protect immigrants, this has implications for labour market outcomes and for the intergenerational transmission of disadvantage. 


\section{References}

Barrett, A. and Y. McCarthy (2008), “Immigrants and Welfare Programmes: Exploring the Interactions between Immigrant Characteristics, Immigrant Welfare Dependence and Welfare Policy”, (2008), with Yvonne McCarthy, Oxford Review of Economic Policy Vol. 24 No. 3.

Barrett, A. and Y. McCarthy (2007), "Immigrants in a Booming Economy: Analysing their Earnings and Welfare Dependence”, Labour: Review of Labour Economics and Industrial Relations Vol. 21 No. 4-5 pp789-808

Brücker, Herbert, Gil S. Epstein, Barry McCormick, Gilles Saint-Paul, Alessandra Venturini and Klaus Zimmermann (2002), "Welfare State Provision”, chapter 5 in Boeri, Tito, Gordon Hanson and Barry McCormick eds. Immigration Policy and the Welfare State, Oxford: Oxford University Press

Dustmann, C., Frattini, T. and Halls, C. (2010), “Assessing the Fiscal Costs and Benefits of A8 Migration to the UK”, Fiscal Studies, Vol. 31 No. 1 pp. 1-41

Hansen, Jörgen and Magnus Lofstrom (2009), “The Dynamics of Immigrant Welfare and Labor Market Behaviour”, Journal of Population Economics Vol. 22 pp. 941-970

Longford, N.T. and Nicodemo, C. (2010), “The Contribution of Social Transfers to the Reduction of Poverty”, IZA Discussion Paper No. 5223

Riphahn, R. T. (2004), 'Immigration Participation in Social Assistance Programs', Applied Economics Quarterly, Vol. 50 No. 4. 